\title{
Development of Web-Based Participatory Trend Forecasting System: urtrend.net
}

\author{
Eui-Chul Jung ${ }^{1}$, SoonJong Lee ${ }^{2}$, HeeYun Chung ${ }^{2}$, BoSup Kim², \\ HyangEun Lee ${ }^{2}$, YoungHak $\mathrm{Oh}^{2}$, YounWoo $\mathrm{Cho}^{2}$, WoongBae $\mathrm{Ra}^{2}$, \\ HyeJin Kwon ${ }^{2}$, and June-Young Lee ${ }^{2}$ \\ ${ }^{1}$ Yonsei University, 50 Yonsei-Ro, SeoDaeMun-Gu, \\ Seoul 120-749, Korea \\ ${ }^{2}$ Seoul National University, 599 GwanAk-Ro, GwanAk-Gu \\ Seoul 151-742, Korea \\ jech@yonsei.ac.kr, leesj1@snu.ac.kr, heeyj2@hanafos.com, \\ equququ@empas.com, xmozil@nate.com, \\ \{onebuttwo, dusn, rnskdl, bluyoung\} @naver.com, \\ hyejin. kwon80@gmail.com
}

\begin{abstract}
The goal of this research is to develop a participatory system that can capture live trend issues and people's latent needs in the issues. Web 2.0 technology is adopted because open and sharable information platform is important for this development. The urtrend.net is developed with three sub systems: issue monitoring \& generation system, imagination \& creation system, and value finding system. This paper focuses on the development of the first and second sub systems. Using the System 1, trend related data are gathered and analyzed to extract emerging trend issues in our lives. Using the System 2, people can join freely the public discussion on the issues from the System 1. System 3 will be developed to analyze people's discussion to provide deep insights for designers. The urtrend.net enables designers and planners to be more creative and innovative because the system will produce more sophisticated trend information with rich and informative resources.
\end{abstract}

Keywords: Participatory System Design, Web 2.0, Trend Forecasting System.

\section{Introduction}

Many trend issues and values come into being continuously in daily life environments and shape our new experience. It is difficult but important to read and manage the trend information because forecasting people in the future is one of competitive factors in many fields such as product design, software design, urban design, architecture, planning or even medicine. By this reason, many institutes and individuals have published trend information regularly. However, many designers and planners must invest a lot of time in order to understand background of the trend information and explore people needs hidden in the trend information. Some trend information providers on the left side in the Figure 1 only deliver trend information one-sidedly with some keywords, descriptions, and design resources. They do not provide channels for people's participation to make the trend information more live. 
Due to the recent development of social networking systems and Web 2.0 technology, many people can share their voice on several issues with others [1]. The items on the lower right side in the Figure 1 are good examples. Among people's voices on the example sites, there are many clues for extracting trend issues and solutions for the issues. People can express their own ideas as one of stakeholders in design activities [2]. However, the data from people are too raw to be used directly, so they must be tuned and interpreted for specific purposes.

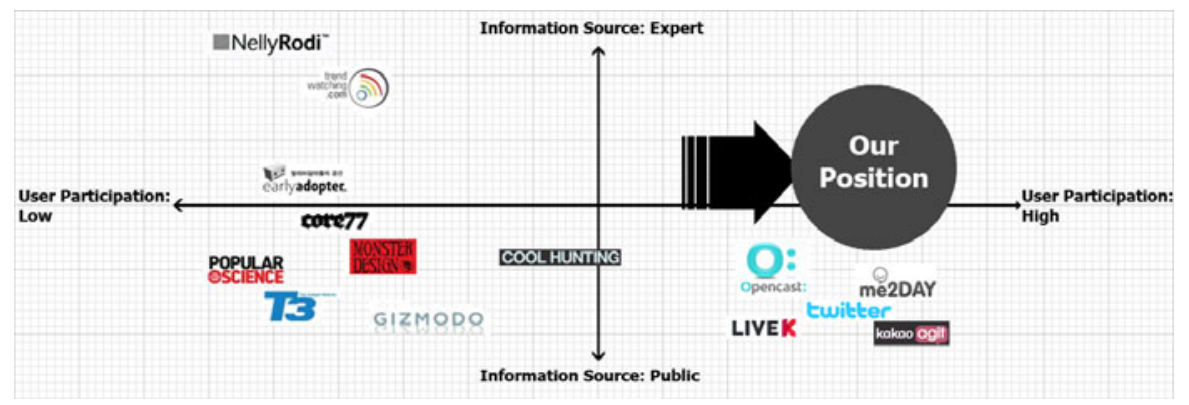

Fig. 1. Positioning of this research

Figure 1 shows how this research is positioned against other trend related institutes and systems. The aim of this research is to develop a people participatory system that can not only make people joined in capturing and discussing trend issues, but also provides insights with experts' opinions on trend issues. The name of the system, 'urtrend,' means that 'you yourself are trend' and/or 'trend is created by you.' The 'urtrend.net' will produce more practical and tangible trend information through people's participation and experts' involvement.

\section{System Overview}

In order to understand such diverse aspects of hidden and latent trend information in our lives and to bridge product and system design processes, it is critical to introduce a mechanism for sharing and integrating trend information.

\subsection{System Structure}

Figure 2 shows the whole mechanism of the 'urtrend.net,' a participatory trend forecasting system. It consists of three systems: issue monitoring \& generation, imagination \& creation, and value finding systems. A design processes can be divided with two axes: 1) defining issues and 2) generating solutions [3]. The 'urtrend.net' is developed by considering this general design process.

The System 1, issue monitoring \& generation system has five sub-systems: the issue note composer, the issue diary composer, the issue diary-tree analyzer, the matrix analyzer, and the issue composer. Many trend resources are gathered and composed in the issue note composer by trend collectors and the collected resources 
are used to compose issue diary which is more refined and valid trend information edited by trained researchers. In order to find hidden pattern and meanings amongst each issue note and issue diary, analyses using issue trees and matrix are conducted. The issue trees are used to find the flow of current phenomena and the matrixes are used to find opportunities of issues hidden in people lives.

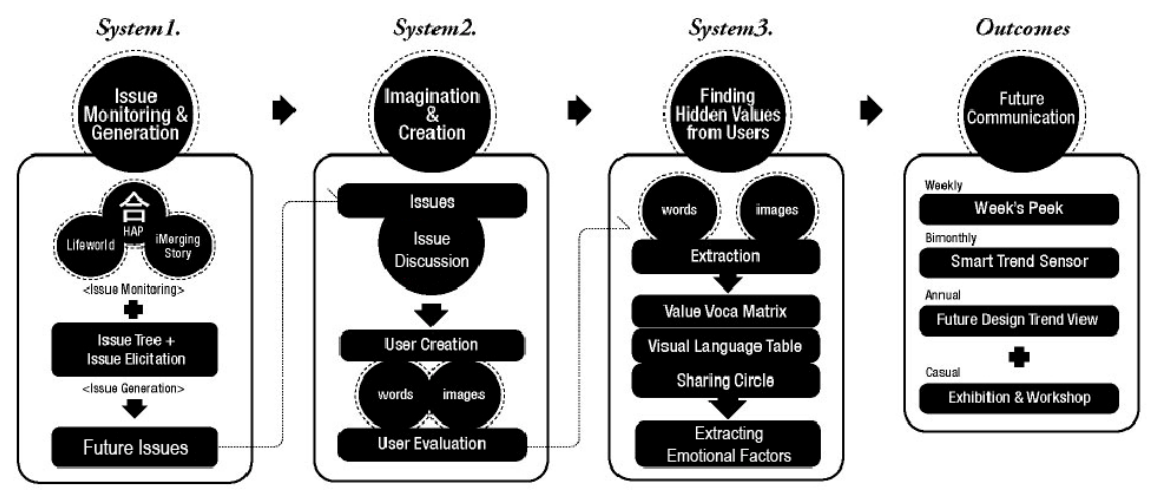

Fig. 2. Structure of 'urtrend.net'

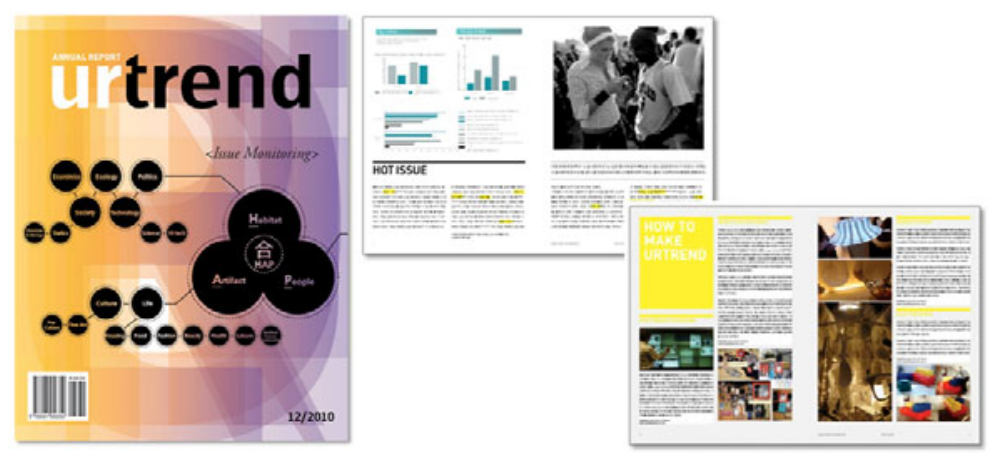

Fig. 3. Expected outcomes from 'urtrend.net'

The System 2 is for imaging and creating the future by referring to the issues with issue notes and diary from the System 1. This system is open in the public, so people who have an interest in each issue can join freely in the issue discussion. The participants can liberally post their ideas and imaginations of the future regarding the issue and each posting can trigger others' participation spontaneously.

The System 3 is developed for designers to concentrate on creative design thinking. The basic concept of the part is that participants leave their latent needs in their writings and images as replies on the System 2. This system can extract the valuable vocabularies from participants for providing insights for designers and system developers. 
The expected outcomes from these systems are weekly, bimonthly, and annual trend reports for stakeholders in each issue and/or project as shown in Figure 3. The reports from these systems can provide richer and more informative contents because each reports contains well-grounded resources, participants' discussions, and the analyses of participants' latent needs.

\subsection{System Architecture}

This paper introduces the development of the 'urtrend.net,' the implemented webbased system. Figure 4 shows the system architecture of 'urtrend.net.' The 'urtrend.net' is implemented on three layered architecture: database server, foundation package, and application package. The database server handles the meta-structure of issue-based project and consists of seven key tables and their sub-tables. Its primary roles are to manage system information, to generate and store project data structure and to handle reports, resources, issues, issue discussion, and users' profiles. The foundation package consists of several classes for implementing shared functions of the system. Modules in the application packages such as report composer, report analyzer, issue composer, issue discussion, people activity analyzer, and stamp manager are developed on the shared platform, so the whole encoded data can be integrated and deployed as the ways people want to utilize.

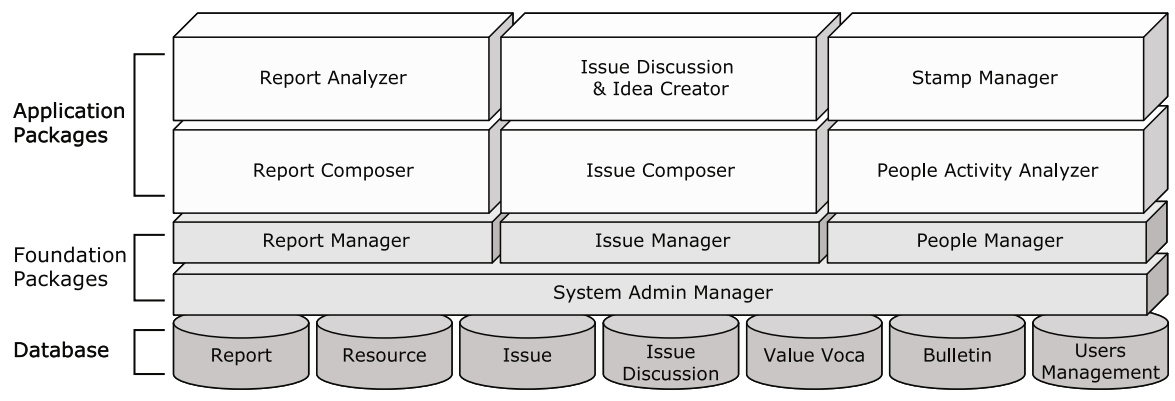

Fig. 4. System architecture of 'urtrend.net'

The implemented key features as shown in Figure 4 are introduced as follows:

1. Issue notes and diaries can be edited and composed with period, primary region and target users, multimedia data, and bibliographic data.

2. Issues can be suggested by analyzing the flow and patterns in issue notes and diaries by plotting them in an analytic frame with axes of time, region, keywords, user group, and so on. The format of issue is important because the issue should work as triggering statements for stimulating participants' imaginations not as questionnaires to be answered.

3. Public open discussion boards provide features to express participants' thoughts in diverse ways.

4. Different user levels such as system administrators, expert panels, researchers, trend collectors, and normal users can be managed to perform their tasks in the 'urtrend.net.' 


\section{Process of Using 'urtrend.net'}

The whole process of using 'urtrend.net' consists of four steps as shown in Figure 5. For better explanation how to utilize 'urtrend.net' for practical purposes, a case study of what and how will you do if you can afford to design your home will be used as an example.

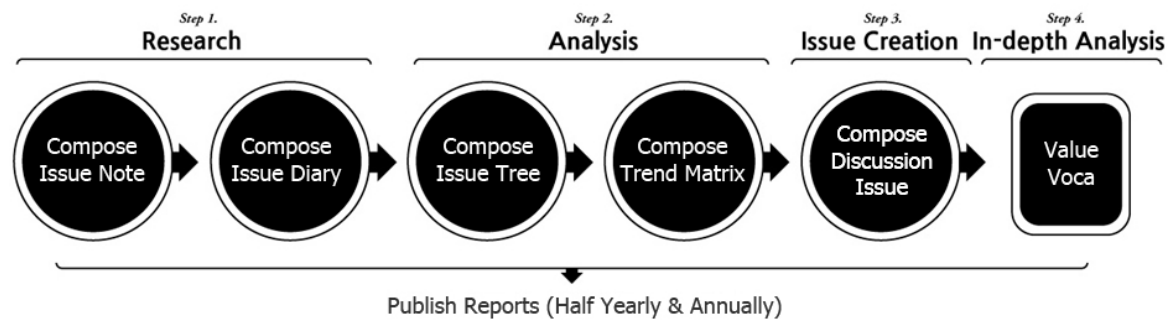

Fig. 5. Process of using 'urtrend.net'

Using this case study, performance of the following four features can be evaluated and refined: 1) methods for framing trend information by integrating multiple resources, 2) methods for managing, encoding, and analyzing trend information using the System 1,3 ) representation and visualization of trend information to suggest new issues, and 4) usability of the System 2 to make participants engaged in the issue discussion voluntarily and seamlessly. This case study can demonstrates that urtrend.net achieved primary goals to provide usable and applicable trend information platform.

\subsection{Step 1: Research}

Collecting diverse data is important for innovative and creative design because they will inspire designers' and planners' insights. Moreover, the data work as criteria at critical decision points for better design results [4].
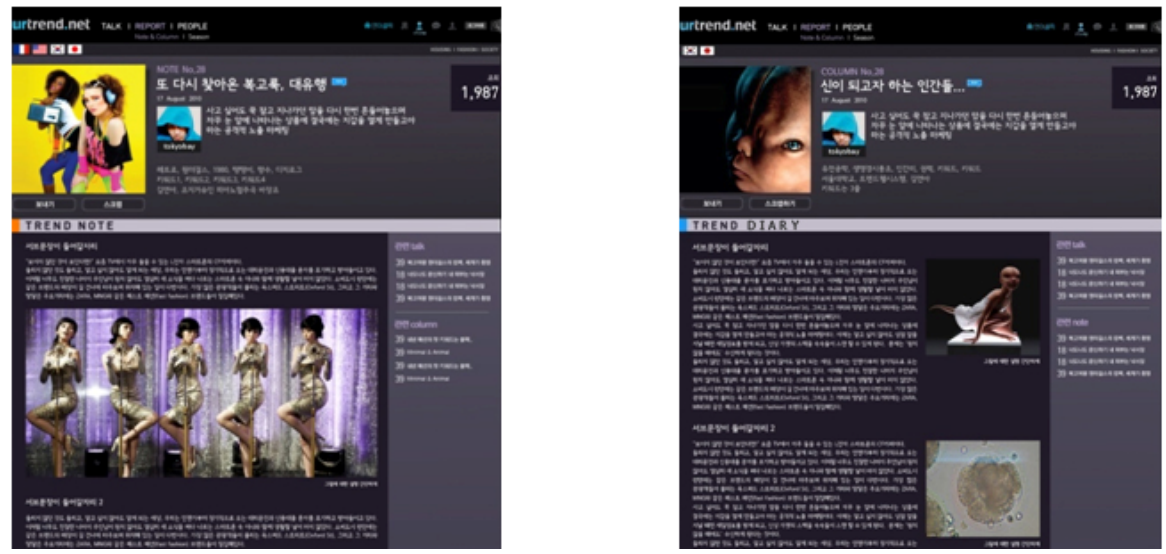

Fig. 6. Issue Note (left) and Issue Diary (right) 
Issue Note. An issue note is collected from many external trend resources such as web sites, magazines, and books as shown in the left of Figure 6. The note contains live and current facts, so it will be used for composing issue diary which shows emerging recent issues. The trend hunters hired and trained by the 'urtrend.net' collect data with the origin of each resource to prevent copyright issues.

Issue Diary. An issue diary is composed by merging several issue notes that contain the shared issues as shown on the right of Figure 6. The diary has links to relevant issue notes, so researchers can refer to the origin if they want to. The diary shows an emerging issues in a certain region, era, and/or people group depending on which aspects are considered when the diary is composed.

\subsection{Step 2: Analysis}

Once issue notes and diary has been collected and composed, analysis will be followed. In order to reveal patterns and meaning hidden in collected trend data, this step is very important. Issue tree and issue matrix methods are used in the step 2.

Issue Tree. Issue trees are methods to find patterns amongst issue diaries. Each issue diary can be connected with others in some aspects. For example, a trend of 'people's pursuing their own characteristic' has some relations with a trend of 'tremendous popularity of house that enables customers to design in their own ways. As shown in Figure 9, there are four types of issue trees. Each picture in the Figure 9 represents issue diary. Time-based tress can be composed by deploying composed issue diaries in a timeline and connect each other by causal relation. Venn Diagram-based tree can be created by nesting one diary into another. Hierarchy-based tree is a kind of bottom up approaches. By categorizing diaries with similarities and naming the each category, the meaning of collected diaries can be revealed. Card sorting method can be used to create hierarchy-based tree. Composite trees can be used to analyze issue diaries by considering several aspects. This method enables researchers to analyze issue diaries in an integrated way.

Trend Matrix. Issue matrix is an issue generating tool by setting industry fields at the $\mathrm{X}$ axis and themes extracted from issue trees at the $\mathrm{Y}$ axis as shown in Figure 8 . When selecting themes for the $\mathrm{Y}$ axis, five criteria are used: durability, extensity, reliability, originality, and potentiality. The high rated themes are selected from issue tree analysis. For example, the social soft mentoring, the third theme at the Y axis, is selected through these processes. It represents the recent phenomenon that people tend to reply on the opinions from popular people on the network who exercise their influence over others due to the development of social network. Many people try to imitate their styles and want to hear their comments. If this trend is applied to housing industry field, the issue of online house life consulting will be suggested as shown inside the bold box at the third row in housing column as shown in Figure 8. By doing this, many hidden and emerging issues in each industry can be discussed. If a company and/or institutes wants to adopt the 'uretrend.net' for a certain research purpose, the relevant field should come into the $\mathrm{X}$ axis for customized analysis. 


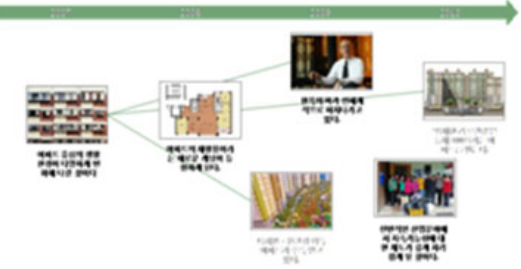

01: Time-based tree

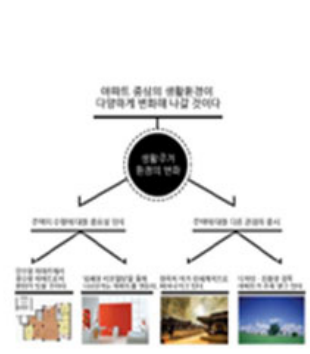

03: Hierarchy-based tree

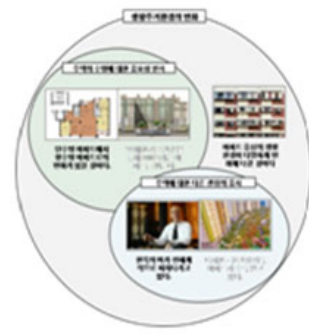

02: Venndiagram-based tree
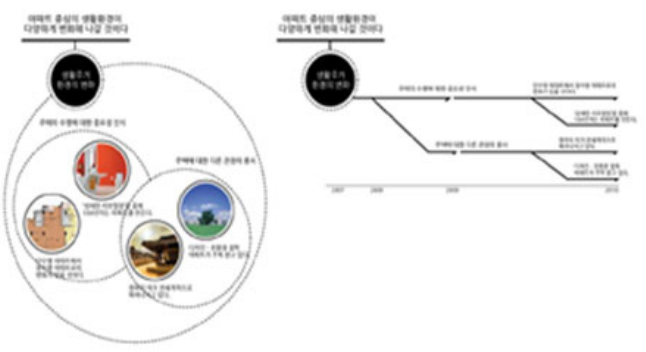

04: Composite trees

Fig. 7. Four types of Issue Trees

\begin{tabular}{|c|c|c|c|c|c|c|c|}
\hline Theme & Industry Field & Housing & Fashion / Beauty & Vehicle & Outdoor Goods & Health & $\pi /$ Electronic \\
\hline $\begin{array}{c}\text { Personal } \\
\text { Governance }\end{array}$ & $\begin{array}{l}\text { Positive } \\
\text { Mind }\end{array}$ & 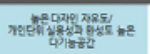 & 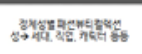 & 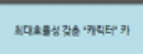 & 79: & 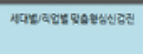 & อแม⿱ \\
\hline Polydentity & $\begin{array}{l}\text { Social, } \\
\text { Sexual, etc. }\end{array}$ & 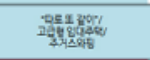 & 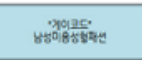 & 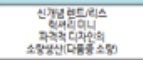 & 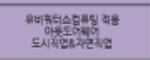 & 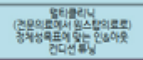 & 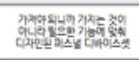 \\
\hline $\begin{array}{l}\text { Social Soft } \\
\text { Mentoring }\end{array}$ & $\begin{array}{c}\text { Star } \\
\text { standard } \\
\text { Manual } \\
\text { clipper }\end{array}$ & MesBongats & 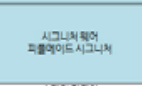 & 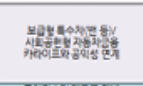 & 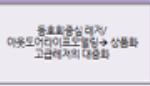 & 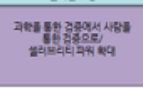 & 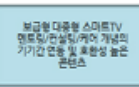 \\
\hline $\begin{array}{l}\text { Eternal } \\
\text { value }\end{array}$ & Humanism & 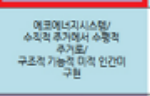 & 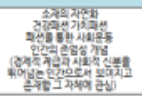 & 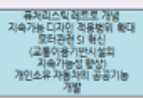 & 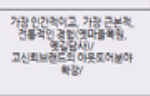 & 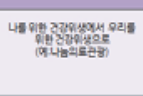 & 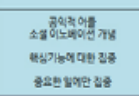 \\
\hline $\begin{array}{l}\text { Niche } \\
\text { Design }\end{array}$ & $\begin{array}{l}\text { Design as a } \\
\text { solution }\end{array}$ & 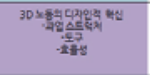 & 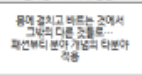 & 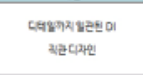 & 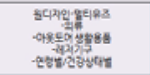 & 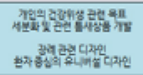 & 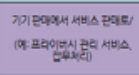 \\
\hline $\begin{array}{l}\text { Extended } \\
\text { UX }\end{array}$ & $\begin{array}{l}\text { Real \& } \\
\text { Cyber }\end{array}$ & 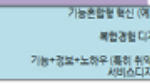 & 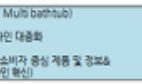 & 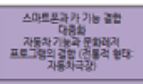 & 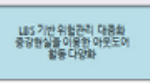 & Utiledth & 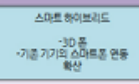 \\
\hline $\begin{array}{l}\text { Extraordina- } \\
\text { riness }\end{array}$ & $\begin{array}{l}\text { Explore } \\
\text { newness }\end{array}$ & 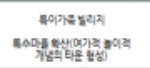 & 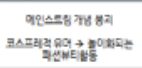 & 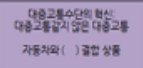 & 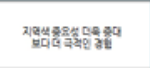 & 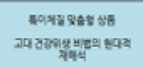 & 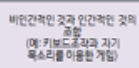 \\
\hline
\end{tabular}

Fig. 8. Example of Issue Matrix

\subsection{Step 3: Issue Creation}

Once an issue matrix is generated, the issue is developed by selecting related issues in each cell to be discussed. This issue selecting step is very important in design process because well defined design opportunities and problems lead to successful design results in many cases. Figure 9 show how the issue, what and how will you do if you can afford to redesign your home in your own ways. Related generated issues in each cell in Figure 8 are selected and filtered in some ways to set the main emerging issue in housing industry field. 


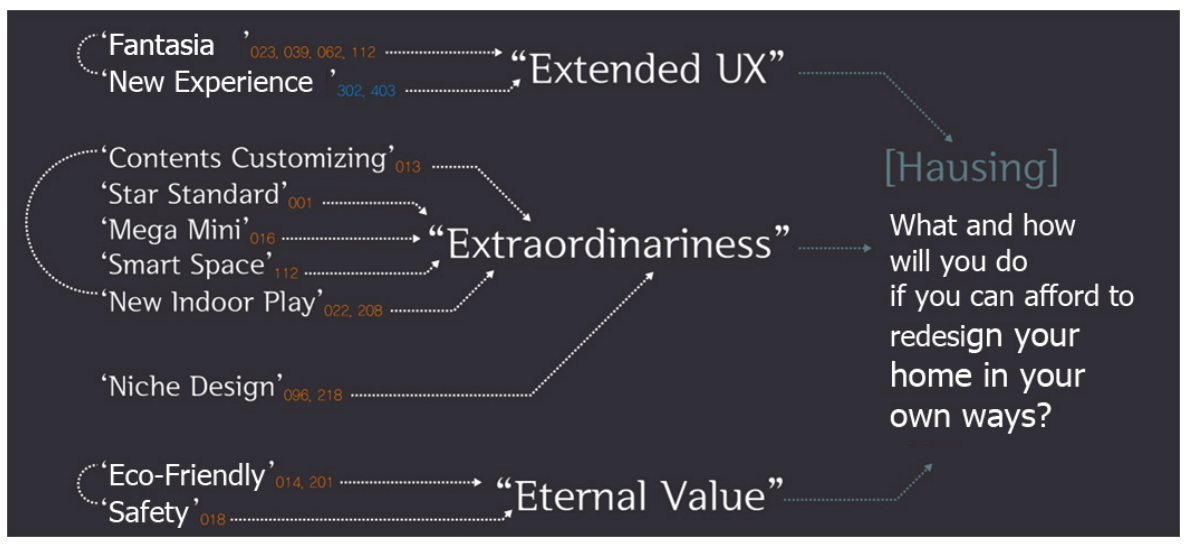

Fig. 9. Example of Issue Matrix

The describing format of an issue should not ask people directly. The issue should provide plentiful insights and background information that make people think in their own ways. That is, it should be a start point of the issue discussion.
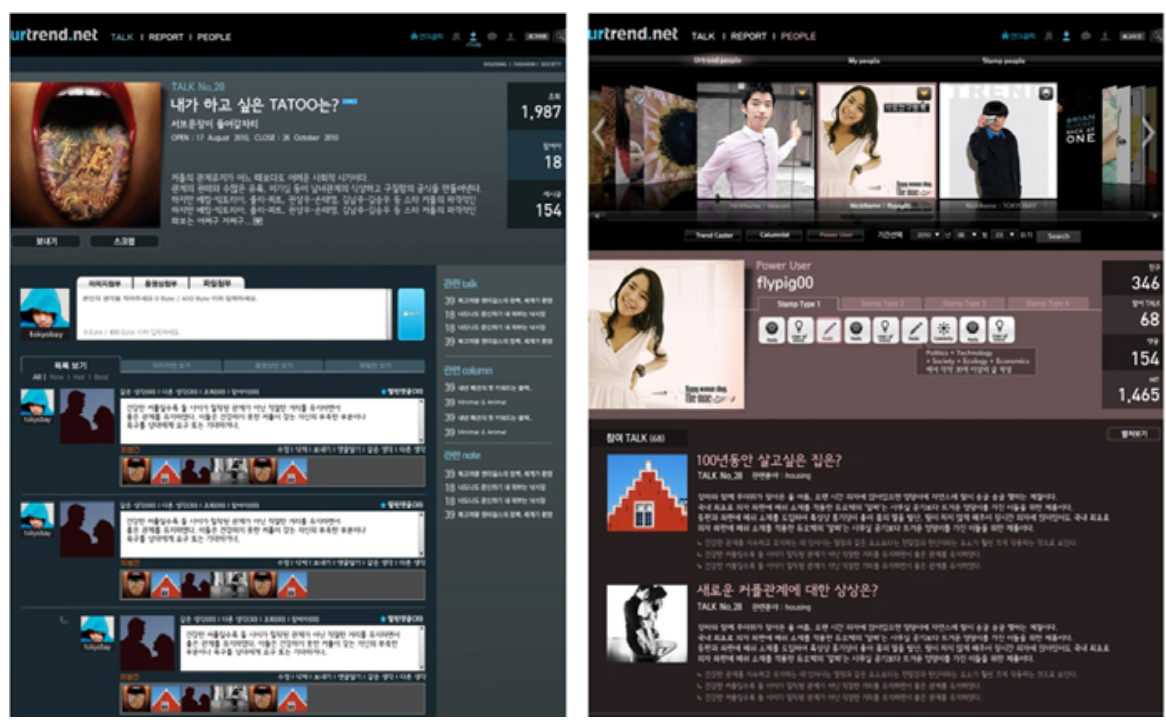

Fig. 10. Issue discussion (left) and people (right)

The left in Figure 10 shows the interface design for issue discussion. People freely join the discussion and upload their ideas and opinions in their own ways. For the rewards for people's volunteer activities, various stamps are designed to represent the level of people in 'urtrend.net.' as shown in the right of Figure 10. This will encourage people's participation. For copyright issues of people's posting, the 'urtrend.net' will pay their ideas by analyzing their activities and stamps, if the postings will be used commercially. 


\subsection{Step 4: In-Depth Analysis}

In this step, valuable vocabularies and images from participants are analyzed to provide insightful information to designers and planner from the users' viewpoints. As people discuss the issue with other, they show their latent thoughts unconsciously in text and images. Those are very important and valuable resource to be analyzed. This analysis processes will be conducted manually, but this is one of benefits of using the 'urtrend.net.'

\section{Conclusion}

The benefits of developing 'urtrend.net' can be summarized as follows: 1) it can manipulate trend forecasting in an integrated way, 2) it can produce trend information from and by crowds, and 3) it can produce practical and concrete trend information.

First of all, the trend forecasting method in the 'urtrend.net' is based on intuition and reasoning from collected facts. Especially, the method can work effectively for the design fields in an integrated way because the method includes not only defining issues and problems but also exploring design ideas and solutions about the issues. It will lead designers and planner to focus on innovative and creative concept development because they can understand the rationales behind the discussion. Secondly, all stakeholders related to a trend can participate in the 'urtrend.net.' People always produce a new trend in their lives, so this system is designed to lead people's participation by adopting Web 2.0 technology. Finally, the trend information from the 'urtrend.net' is not abstract but concrete because many imaginations about the future life and products come up as issues are composed and discussed. By this reason, the trend information and ideation in this system will be more persuasive and informative.

For the further evaluation of using the 'urtrend.net,' more applicable case studies should be conducted. The studies will demonstrate its effectiveness to frame trend information reflecting different resources and to support composing various analytical, representational and synthetic tools for product and system design in general.

\section{References}

1. O'Reilly, T.: What is Web 2.0 (2005), http://oreilly.com/web2/archive/what-is-web-20.html

2. Tapscott, D., Williams, A.D.: Wikinomics: how mass collaboration changes everything, p. 324. Portfolio, New York (2006)

3. Ulrich, K.T., Eppinger, S.D.: Product design and development, 4th edn. McGraw-Hill Higher Education, Boston (2008)

4. Hippel, E.V.: Democratizing innovation. MIT Press, Cambridge (2005) 